\title{
Prostate Infection, CTCAE
}

National Cancer Institute

\section{Source}

National Cancer Institute. Prostate Infection, CT CAE. NCI Thesaurus. Code C143783.

A disorder characterized by an infectious process involving the prostate gland. 